\title{
Disentangling the effects of climate and people on Sahel vegetation dynamics
}

\author{
J. W. Seaquist ${ }^{1}$, T. Hickler ${ }^{1}$, L. Eklundh ${ }^{1}$, J. Ardö ${ }^{1}$, and B. W. Heumann ${ }^{2}$ \\ ${ }^{1}$ Department of Physical Geography and Ecosystems Analysis, Geobiosphere Science Centre, Lund University, Sölvegatan \\ 12, 223 62, Lund, Sweden \\ ${ }^{2}$ Department of Geography, University of North Carolina at Chapel Hill, Saunders Hall, Campus Box 3220, Chapel Hill, NC \\ 27599-3220, USA
}

Received: 1 July 2008 - Published in Biogeosciences Discuss.: 7 August 2008

Revised: 20 February 2009 - Accepted: 25 February 2009 - Published: 26 March 2009

\begin{abstract}
The Sahel belt of Africa has been the focus of intensive scientific research since the 1960s, spurred on by the chronic vulnerability of its population to recurring drought and the threat of long-term land degradation. But satellite sensors have recently shown that much of the region has experienced significant increases in photosynthetic activity since the early 1980 s, thus re-energizing long-standing debates about the role that people play in shaping land surface status, and thus climate at regional scales. In this paper, we test the hypothesis that people have had a measurable impact on vegetation dynamics in the Sahel for the period 19822002. We compare potential natural vegetation dynamics predicted by a process-based ecosystem model with satellitederived greenness observations, and map the agreement between the two across a geographic grid at a spatial resolution of $0.5^{\circ}$. As aggregated data-model agreement is very good, any local differences between the two could be due to human impact. We then relate this agreement metric to state-of-theart data sets on demographics, pasture, and cropping. Our findings suggest that demographic and agricultural pressures in the Sahel are unable to account for differences between simulated and observed vegetation dynamics, even for the most densely populated areas. But we do identify a weak, positive correlation between data-model agreement and pasture intensity at the Sahel-wide level. This indicates that herding or grazing does not appreciably affect vegetation dynamics in the region. Either people have not had a significant impact on vegetation dynamics in the Sahel or the identification of a human "footprint" is precluded by inconsistent or subtle vegetation response to complex socio-environmental
\end{abstract}

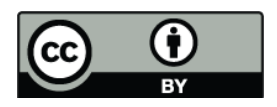

Correspondence to: J. W. Seaquist (jonathan.seaquist@nateko.lu.se) interactions, and/or limitations in the data used for this study. We do not exclude the possibility of a greater human influence on vegetation dynamics over the coming decades with changing land use.

\section{Introduction}

The Sahel belt of Africa has been the focus of intensive scientific research in recent decades, spurred on by the chronic vulnerability of its population to recurring drought and the threat of long-term land degradation. Century-long records of annual rainfall totals show that a lengthy period of desiccation began in the mid-1960s, accompanied by a marked decrease in interannual rainfall variability (Hulme, 2001). Evidence is mounting that the rainfall climate of the Sahel is ultimately driven by changes in ocean circulation and sea surface temperatures and further amplified by internal nonlinear biogeophysical feedback mechanisms that operate between the vegetation and the atmosphere (e.g. Zeng et al., 1999; Wang and Eltahir, 2000; Giannini et al., 2003). This feedback is thought to have led to an abrupt change to a persistently drier climate compared to the first half of the 20th century (Foley et al, 2003).

Recent research has re-invigorated long-standing debates about the direct impact people have on observed changes in the Sahel's land cover status (e.g. Hein and de Ridder, 2006; Prince et al., 2007). The paradigm of geographically extensive and irreversible land degradation has been challenged by satellite observations of vegetation greenness (NDVI Normalized Difference Vegetation Index) that showed the return of vegetation in years that received favourable rainfall (Helldén, 1991; Tucker et al., 1991). Even more recent findings using data from the same satellite sensors show a

Published by Copernicus Publications on behalf of the European Geosciences Union. 
widespread increase in photosynthetic activity since the early 1980s (Eklundh and Olsson, 2003; Olsson et al., 2005; Hermann et al., 2005, Seaquist et al. 2006; Heumann et al., 2007). Proposed explanations have included increasing rainfall, $\mathrm{CO}_{2}$ enhancement effects, agricultural intensification, extensification, and land abandonment stemming from socioeconomic change and conflict.

Using a process-based vegetation model, LPJ-DGVM (Lund Potsdam Jena-Dynamic Global Vegetation Model), Hickler et al. (2005) identified rainfall change as the primary regulator of vegetation dynamics in the Sahel between 1982 and 1998 (with $\mathrm{CO}_{2}$ having a minor positive influence), albeit at the aggregated level. They closely reproduced the satellite-observed greening trend and its interannual variability by holding all driving variables in the model constant except rainfall. In another study, Hermann et al. (2005) used a data-driven approach to reach a similar conclusion by statistically relating gridded, satellite-derived rainfall data (at $2.5^{\circ}$ and $1.0^{\circ}$ spatial resolution) with satellite-based NDVI observations (at $8 \mathrm{~km}$ spatial resolution) for the period 1982-2003. After removing the influence of rainfall from the NDVI data, spatially coherent, statistically significant residual trends remained, showing where the land surface has either been greening faster (possibly indicating land "rehabilitation") or slower (possibly indicating land degradation) than can be accounted for by rainfall alone. These findings are echoed by Evans and Geerken (2004) and Wessels et al. (2007) who used similar NDVI-rainfall residual trend analyses (at NDVI resolution of $8 \mathrm{~km}$ and interpolated rainfall data) in order to isolate possible human-induced degradation signals in the drylands of Syria and the rangelands of South Africa respectively. Additionally, Li et al. (2004) applied NDVI-rainfall regression diagnostics to assess land cover performance in Senegal.

Though Hickler et al. (2005) presented convincing evidence that rainfall governs vegetation dynamics in the Sahel at the aggregated level, the spatial details of data-model agreement were not resolved. It is possible that minor differences in aggregated simulated versus observed vegetation dynamics stem from substantial differences in sub-regions where human impact may be measurable. Since the LPJDGVM simulates potential natural vegetation while satellitederived greenness represents actual vegetation, differences between the two could be due to anthropogenic pressures. The possibility therefore exists that the human "footprint" in dryland regions, including the Sahel, may be significant enough to alter broad-scale biogeophysical processes, carbon cycling, and climate through direct impact on vegetation dynamics. But the human impact hypothesis remains largely untested for the Sahel at broad spatial extents.

In this paper, we test the hypothesis that people have had a measurable impact on vegetation dynamics in the Sahel for the period 1982-2002. Like Hickler et al. (2005), we compare vegetation dynamics predicted by the LPJ-DGVM with satellite-based greenness observations, but we extend their approach by distributing model output across a geographic grid. We then relate a data-model agreement metric to stateof-the-art data sets on demographics, pasture, and cropping intensity on a cell-by-cell basis. If human impact has been significant, we should then expect to find an association between data-model differences and land use/population pressures.

\section{Data and methods}

\subsection{Satellite-derived greenness data}

We used the Global Inventory Modeling and Mapping Studies (GIMMS) 10-day maximum value composite NDVI dataset derived from the National Oceanic and Atmospheric Administration's (NOAA) series of Advanced Very High Resolution Radiometer (AVHRR) instruments with a spatial resolution of $8 \mathrm{~km}$ (Tucker et al., 2005). The NDVI is computed from the red and near infrared bands of the AVHRR sensor and is correlated with photosynthetic activity and leaf area index of green vegetation (Sellers, 1989). The NDVI also reduces unwanted variations in the data due to topography, sensor calibration, and viewing geometry, while maximum value compositing reduces the effects of cloud cover and the atmosphere (Holben, 1986). The GIMMS data set has been corrected for sensor differences, sensor drift, and the effects of volcanic eruptions. We extracted peak NDVI observations (NDVI $I_{\max }$ ) for each growing season from 1982-2002. We then projected them to a geographic grid while re-sampling to $0.5^{\circ}$ (using bi-linear interpolation) in order to match the resolution of the climate input data used for driving LPJ-DGVM. Data were extracted for $12^{\circ} \mathrm{N}$ to $20^{\circ} \mathrm{N}$ and $19^{\circ} \mathrm{W}$ to $40^{\circ} \mathrm{E}$ (Fig. 1). A southern limit of $12^{\circ} \mathrm{N}$ was chosen to avoid saturation of the NDVI observations which would make vegetation changes difficult to discern.

\subsection{Vegetation model}

LPJ-DGVM is a coupled biogeography-biogeochemistry model, which incorporates process-based representations of terrestrial vegetation dynamics and biogeochemical cycling. A full description of the model can be found in Sitch et al. (2003). Processes governing water uptake by vegetation were updated by Gerten et al. (2004). The model is used by a broad community of global-change researchers ${ }^{1}$ and has, for example, been shown to successfully reproduce the distribution of global biomes (Sitch et al., 2003; Hickler et al., 2006), variations in net primary production (NPP) across biomes (Hickler et al., 2006; Zaehle et al., 2005), satellitederived high-latitude greening trends in the 1980s and 1990s (Lucht et al., 2002), and site-scale and global patterns in the

\footnotetext{
1 available at: http://www.pik-potsdam.de/research/cooperations/lpjweb
} 
water balance of terrestrial ecosystems (Gerten et al., 2004). We used the C++ implementation of LPJ-DGVM within the generalized modelling framework LPJ-GUESS (Smith et al., 2001).

\subsection{Modelling protocol and climate data}

LPJ-DGVM was driven with monthly data for air temperature, precipitation, number of rain days, and sunshine hours from the global CRU05 dataset for the region bounded by $12^{\circ} \mathrm{N}$ to $20^{\circ} \mathrm{N}$ and $19^{\circ} \mathrm{W}$ to $40^{\circ} \mathrm{E}$ at a $0.5^{\circ}$ resolution (Mitchell and Jones, 2005). Monthly temperature and sunshine data were interpolated to provide quasi-daily time series. Daily precipitation fields were generated with a stochastic weather generator (Gerten et al., 2004). Annual global atmospheric $\mathrm{CO}_{2}$ concentrations were obtained courtesy of the Carbon Cycle Model Linkage Project (McGuire et al., 2001) and TRENDS ${ }^{2}$. Climate data for a 1000-year model spin-up were derived from the same data by repeating detrended values of the climate input for 1901-1930, using pre-industrial $\mathrm{CO}_{2}$ content of the atmosphere. The model was run as to simulate the potential natural vegetation; information on land cover was not included. Growing season maximum LAI $\left(\mathrm{LAI}_{\max }\right)$ were then extracted for the period 1982-2002.

\subsection{Data-model agreement and greenness trends}

Spearman's rank-order correlation coefficient was used to gauge data-model agreement $\left(r_{s[\mathrm{NDVI}-\mathrm{LAI}]}\right)$. Spearman's coefficient varies between -1 and +1 , where large positive values indicate strong agreement, large negative values indicate strong disagreement, and values near 0 indicate random agreement. The purpose of this coefficient is to measure the association between two variables (e.g. LAI $_{\max }$ and $\mathrm{NDVI}_{\max }$ ) whose scores are in rank order (McGrew Jr. and Monroe, 2000). The reason for choosing this coefficient was to remove any non-linearity that could undermine the detection of a monotonic relationship between $\mathrm{LAI}_{\max }$ and $\mathrm{NDVI}_{\max }$.

We chose to compare $\mathrm{LAI}_{\max }$ with $\mathrm{NDVI}_{\max }$ because the use of other vegetation parameters would require a number of additional, potentially complicating assumptions. For example, while the comparison of integrated NDVI and annual NPP may seem better for capturing the impact of land use on vegetation (as the NDVI integral is often assumed to be a proxy for NPP), integrated NDVI more realistically represents the amount of photosynthetically active radiation absorbed by the plant canopy rather than plant growth, rather than NPP (Prince, 1991).

For comparison, we also applied a temporal trend analysis the $\mathrm{NDVI}_{\max }$ observations. Curves were fitted to every cell using OLS (ordinary least-squares regression). The

\footnotetext{
2 available at:

http://cdiac.esd.ornl.gov/trends/co2/contents.htm
}

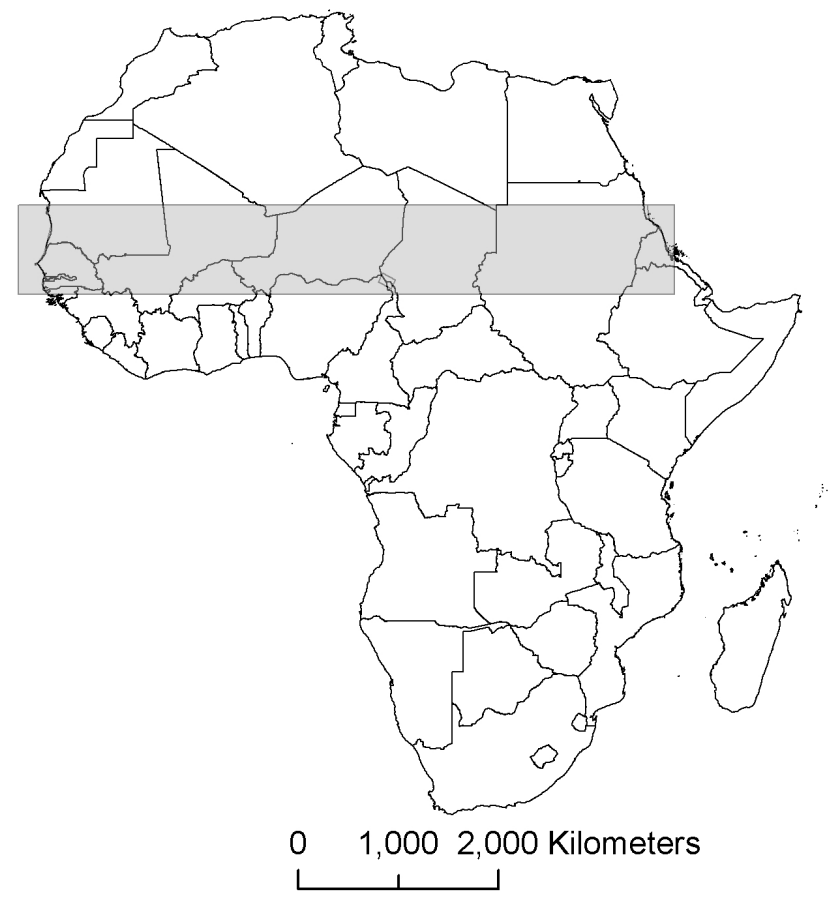

Fig. 1. Study area, restricted to $12^{\circ} \mathrm{N}$ to $20^{\circ} \mathrm{N}$ and $19^{\circ} \mathrm{W}$ to $40^{\circ} \mathrm{E}$.

slope coefficient of the regression was used for determining the sign and magnitude of the trends. It is worth noting that vegetation change, particularly in drylands, may not always change linearly, but most studies that analyze Sahel greening at the broad extent apply OLS (e.g. Eklundh and Olsson, 2003; Olsson et al., 2005; Hermann et al., 2005; Heumann et al., 2007). We therefore used an OLS analysis for contextualizing our results.

\subsection{Population density and land use}

Gridded data on population density (persons $\mathrm{km}^{-2}$ ) for the years 1980, 1990, and 2000 were downloaded from the Africa Population Distribution Database ${ }^{3}$, resampled to a $0.5^{\circ}$ resolution and subset to the same spatial extent as all other layers (Fig. 2a). These grids were derived from census data, transportation networks (roads, railroad, and navigable rivers) and information on the location of urban centres. The underlying assumption for the generation of these data is that population density is strongly dependent on accessibility via transportation routes.

We used the Agricultural Lands in the Year 2000 (AL2000) data set described in Ramankutty et al. $\left(2008^{4}\right)$. This is a state-of-the-art global data set depicting cropland use and pasture use intensity (values ranging between 0 and

\footnotetext{
3 available at:

http://na.unep.net/globalpop/africa/Africa_index.html

4 available at:

http://www.geog.mcgill.ca/ nramankutty/Datasets/Datasets.html
} 


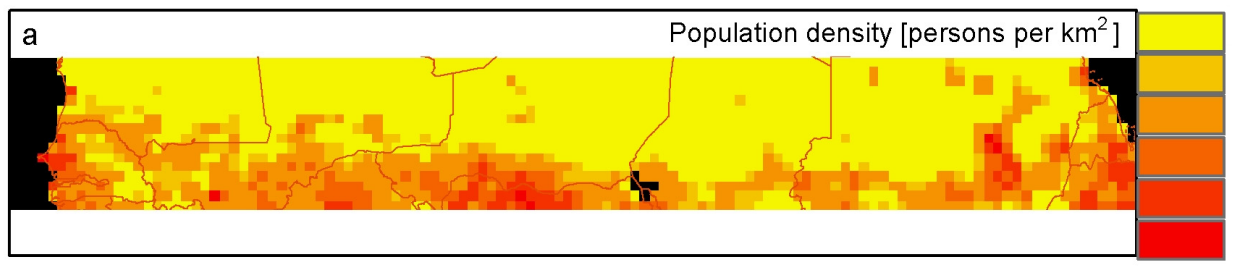
0-5
5-10
10-50
50-100
100-300
$>300$
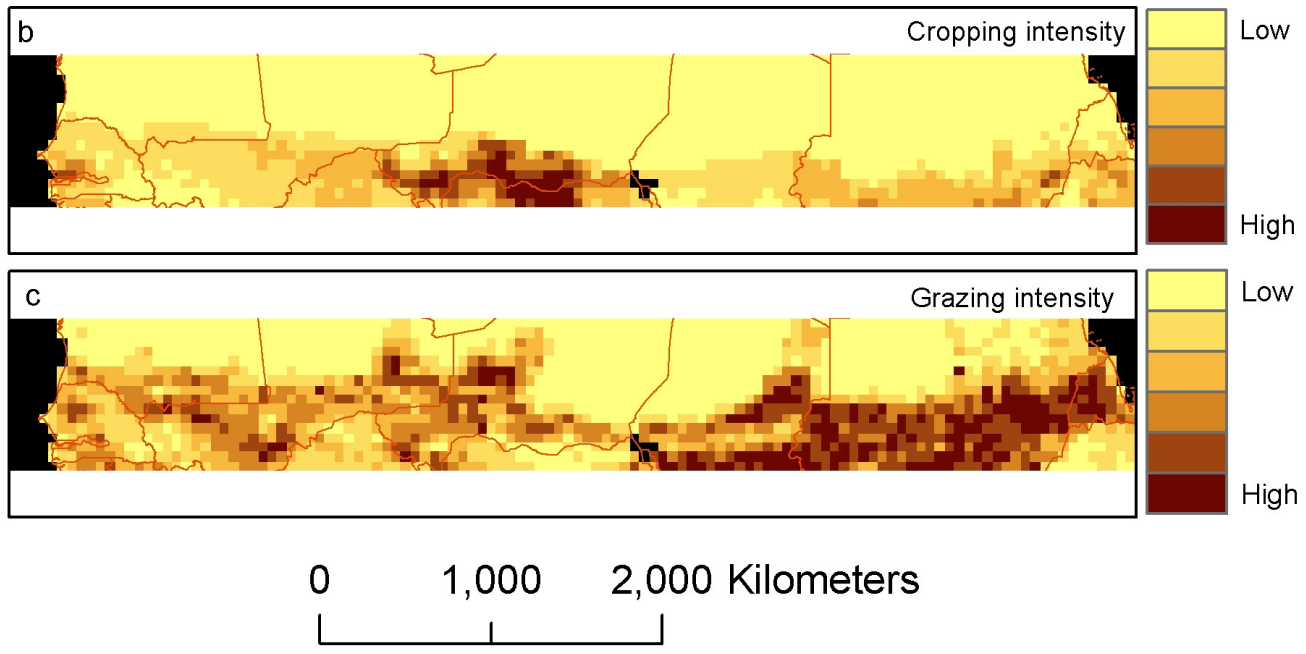

Fig. 2. Population density for year 2000 (Nelson, 2004) (a), cropping intensity ca. year 2000 (Ramankutty et al., 2008) (b), and grazing intensity ca. year 2000 (Ramankutty et al., 2008) (c).

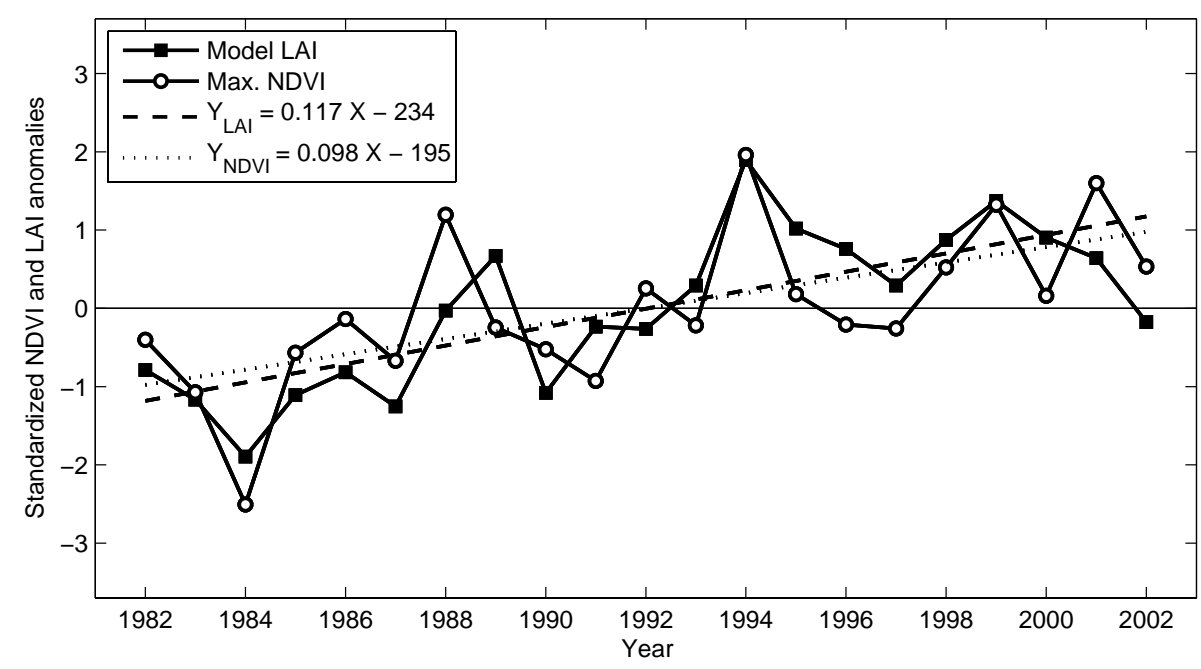

Fig. 3. Aggregated standardized anomalies of modelled $\mathrm{LAI}_{\max }$ and observed NDVI $\max 1982-2002$, and linear regression lines for the data vs. time.

1) at a spatial resolution of $5 \mathrm{~min}$ (approximately $10 \mathrm{~km}$ ). The AL2000 was produced by merging agricultural inventory data for different countries with satellite-derived land cover data derived from Boston University's Moderate Resolution Imaging Spectrometer (MODIS) land cover product and Satellite Pour l'Observation de la Terre (SPOT) Vegeta- tion's Global Land Cover 2000 product. This is the first data set of its kind to attach statistical confidence intervals to land use estimates. We extracted data for the study area, while coarsening the resolution to $0.5^{\circ}$ using bi-linear interpolation (see Fig. 2b and c). 


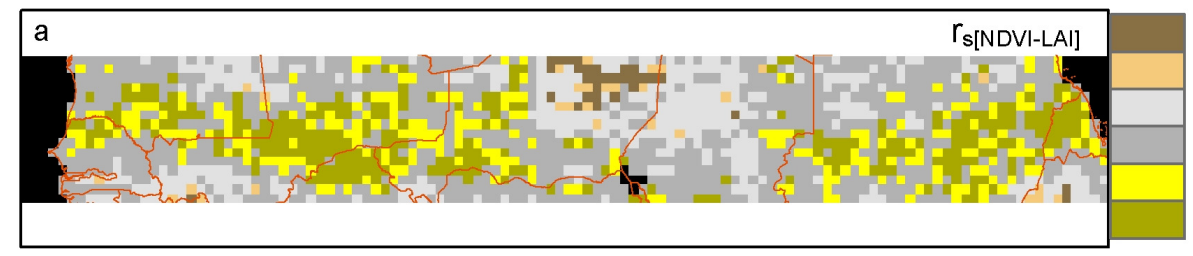

Strongly negative

Negative

Negative, no significance

Positive, no significance

Positive

Strongly positive

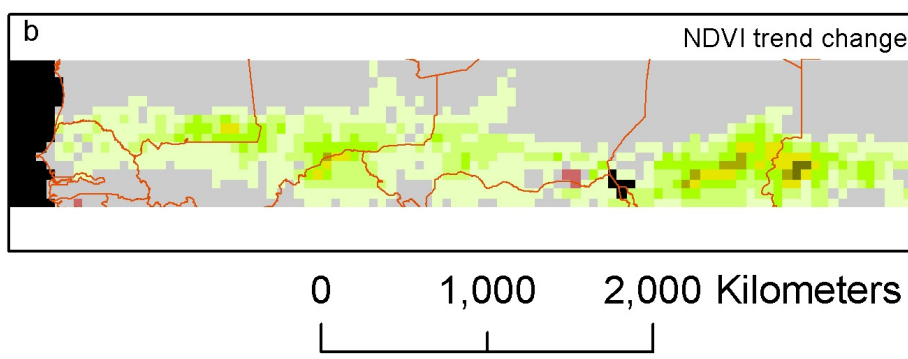

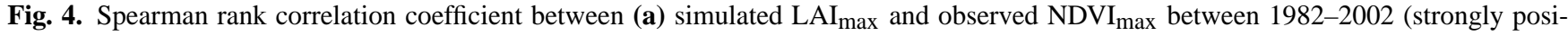
tive/negative and positive/negative denote statistical significance thresholds of $\alpha=0.01, r_{s}[\mathrm{NDVI}-\mathrm{LAI}]=0.55$, and $\alpha=0.05, r_{s}[\mathrm{NDVI}-\mathrm{LAI}]=0.44$, respectively), and (b) NDVI $_{\max }$ trend change 1982-2002 expressed as a percentage.

\subsection{Data-model agreement vs. population density and land use}

Finally, we related level of data model agreement $\left(r_{s}\right.$ [NDVI-LAI] $)$ to estimates of population density and its change from the Africa Population Distribution Database, as well as cropping and pasture from the AL2000 for all terrestrial surfaces $(\mathrm{n}=1780)$.

\section{Results}

\subsection{Data-model comparison}

On an aggregated level, LPJ-DGVM generally reproduced the overall trend and pattern of interannual variation in observed vegetation greenness between 1982 and 2002 (Fig. 3). The simulated mean $\mathrm{LAI}_{\max }$ was 3.15 while the mean $\mathrm{NDVI}_{\max }$ was 0.36 , averaged over all cells for all years. Regressing the yearly spatial mean $\mathrm{NDVI}_{\max }$ anomaly against the yearly spatial mean $\mathrm{LAI}_{\max }$ anomaly yields a Pearson correlation coefficient 0.77 with a small bias $\left(\mathrm{LAI}_{\max }=0.77 * \mathrm{NDVI}_{\max }-0.004\right)$.

Geographically, $r_{s[\mathrm{NDVI}-\mathrm{LAI}]}$ is fair-to-strong for a relatively contiguous band stretching from the coastal area of Northern Senegal, Southern Mauritania, Central Mali, and Western Niger (Fig. 4a). Agreement drops off in Chad before picking up again throughout Central Sudan and into Eritrea. 542 cells $\left(0.5^{\circ}\right)$ show statistically significant positive correlations, corresponding to $30.4 \%$ of the total land area (mean $r_{s[\mathrm{NDVI}-\mathrm{LAI}]}=0.58, \alpha=0.05$, threshold $r_{s[\mathrm{NDVI}-\mathrm{LAI}]}$ for statistical significance $=0.44$ ). A large patch of strong disagreement is found in Northern Niger, with smaller patches in Southwest Mali and Ethiopia. 61 cells show statistically sig- nificant negative correlations, corresponding to $3.4 \%$ of the total land area (mean $r_{S[\mathrm{NDVI}-\mathrm{LAI}]}=-0.56, \alpha=0.05$, threshold $r_{s[\text { NDVI-LAI] }}$ for statistical significance $=-0.44$ ).

For comparison, Fig. $4 \mathrm{~b}$ shows the strength of the trends in $\mathrm{NDVI}_{\max }$ for $1982-2002$ in percent $(\alpha=0.05)$. Statistically significant increases in $\mathrm{NDVI}_{\max }$ occur in a relatively uninterrupted band stretching from the Atlantic coast to the Red Sea. Strongest trends occur in Central Chad and Western Sudan with increases in excess of $100 \%$ for the 1982 to 2002 period. 683 cells or $38.3 \%$ of the area show trends that are statistically significant. Negative trends are confined to three cells in the southwest corner of Niger with decreases around $20 \%$.

$r_{s[\mathrm{NDVI}-\mathrm{LAI}]}$ tends to be higher for areas with strong positive $\mathrm{NDVI}_{\max }$ trend correlation coefficients (Fig. 5a). Poor data-model agreement is associated with negative trends in observed vegetation indicating poor model performance for these areas. However, negative changes in $\mathrm{NDVI}_{\max }$ are generally much smaller than positive trends when expressed as changes in percent (Fig. 5b).

\subsection{Relationship between $r_{s[\mathrm{NDVI}-\mathrm{LAI}]}$ and population density and land use}

There is no strong association between $r_{s[\mathrm{NDVI}-\mathrm{LAI}]}$ and either total population (Fig. 6a), relative changes in population density between 1980 and 2000 (Fig. 6b), or cropping intensity (Fig. 6c); Pearson correlation coefficients $r,<0.12$ (i.e. less than $2 \%$ of the variance explained). But for areas experiencing depopulation, data-model agreement is always positive (Fig. 6b). The mean population density was 17.5 persons $\mathrm{km}^{-2}$ with a maximum of 994.1 persons $\mathrm{km}^{-2}$. Though not reproduced here, a scatter-plot of data-model 

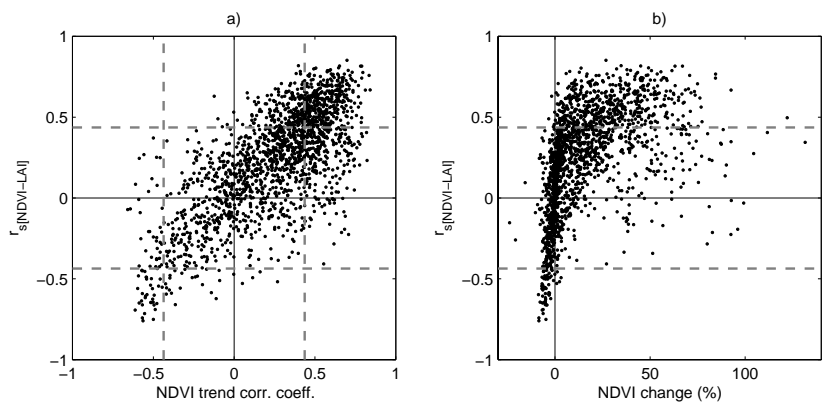

Fig. 5. Plots of Spearman rank correlation coefficient $\left(r_{s[\mathrm{NDVI}-\mathrm{LAI}]}\right)$ against (a) $\mathrm{NDVI}_{\max }$ trend correlation coefficients, and (b) change in $\mathrm{NDVI}_{\max }$ over time. Dashed grey lines indicate thresholds of statistical significance $(\alpha=0.05)$ for data-model comparison and temporal least-squares regression for $\mathrm{NDVI}_{\max }$.

agreement versus the absolute change in population density between 1980 and 2000 was very similar to Fig. 6a. Rates of population growth throughout the period ranged from -0.54 to 26.5 persons $\mathrm{km}^{-2} \mathrm{yr}^{-1}$ with a mean of $0.36 \mathrm{~km}^{-2} \mathrm{yr}^{-1}$. Relative change in population ranges from $-39.3 \%$ to $492.4 \%$, with a mean of $43.3 \%$. However, $r_{s}$ [NDVI-LAI] increases with pasture intensity (Fig. 6d), indicating that the greater proportion of pasture in an area, the better the model simulates actual vegetation. For this relationship, $r=0.46$. Log-transforming population and agricultural parameters do not result in increased levels of association with data-model agreement, and there were no strong associations between population, cropping intensity, and grazing intensity.

Since most of the densely populated areas occur within or nearby urban centres, we also investigated the hypothesis that data-model agreement would be most affected by population and land use only in those areas undergoing the most rapid population growth. We therefore isolated areas with different thresholds in population growth between 1980 and 2000, and retained the threshold that gave an acceptable sample size ( 2.4 persons $\mathrm{km}^{-2} \mathrm{yr}^{-1} \mathrm{n}=58$ ). We then repeated our analysis, relating data-model agreement to population/population change, cropping, and pasture. $r$ for $r_{s[\mathrm{NDVI}-\mathrm{LAI}]}$ versus pasture was 0.58. $r$ for all other relationships was below 0.07 . The results did not vary appreciably for neighbouring population growth thresholds, either higher or lower.

\section{Discussion}

Demographic and agricultural pressures in the Sahel were largely unable to account for differences between simulated and observed vegetation dynamics for the period 1982-2002. However, we did identify a positive relationship between data-model agreement and pasture intensity at the Sahelwide level (Fig. 6d). As the model predicts potential natural vegetation dynamics (without animal grazing and human in-
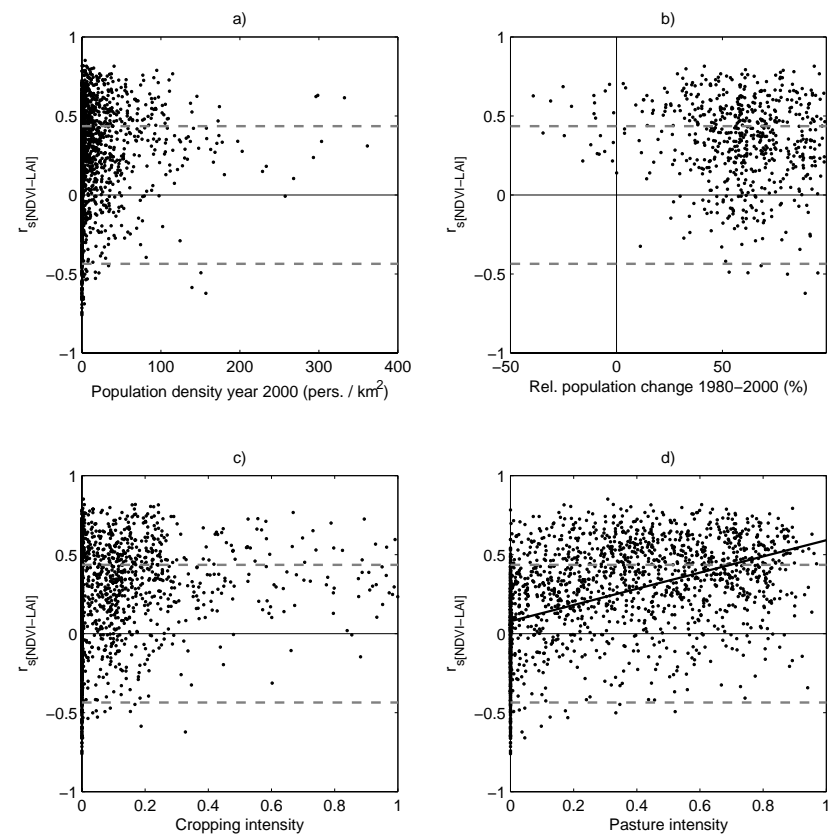

Fig. 6. Plots of Spearman rank correlation coefficient $\left(r_{s[\mathrm{NDVI}-\mathrm{LAI}]}\right)$ against (a) population density in the year 2000, (b) relative population change from 1980 to 2000, (c) cropping intensity, and (d) pasture intensity. Dashed grey lines indicate thresholds of statistical significance for data-model comparison $(\alpha=0.05)$. Solid line in (d) indicates regression for Spearman rank correlation coefficient vs. pasture intensity; $\mathrm{y}=0.078+0.513 \mathrm{x} ; r=0.46$.

fluences), this suggests that livestock grazing is generally not associated with variations in greenness in the Sahel, at least at the scale of our study. Once possible interpretation is that the pastoralists, along with their herds, slowly migrated to the areas that were receiving plentiful rainfall over the period. As mentioned in Sect. 3.2, data-model agreement is always positive for areas experiencing depopulation (Fig. 6b), but most of these cells already have very low population densities and occur within the broad area of greening that roughly corresponds with the pastoral zone. And since there was a moderate relationship between datamodel agreement and pasture with high population growth rates (2.4 persons $\mathrm{km}^{-2} \mathrm{yr}^{-1} \mathrm{n}=58$ ) from between 1980 and $2000(r=0.58)$, the implication is that areas near urban centres did not undergo degradation, but on the contrary, became greener. It also re-enforces the hypothesis that animal density does not appreciably impact vegetation dynamics, at least at this scale. This finding is consistent with the non-equilibrium hypothesis of rangeland ecology (e.g. Behnke and Scoones, 1993).

It is important to keep in mind that human modification of vegetation over large areas occurs within a social context and can be the result of a myriad of decisions and behaviours that may either act to suppress or augment vegetation amount and its variability (Turner, 2003). If consistent vegetation 
response to human modification is dependent on the local context, then relationships between data-model agreement and human activity measures might be embedded within the scatter-plots shown in Fig. 6a-d. We provisionally tested this hypothesis by focusing on relationships for an area of large, positive data-model agreement extending from Western Mali to Western Niger $(n=190)$, and an area of randomto-negative data-model agreement stretching from Eastern Niger to Eastern Chad ( $\mathrm{n}=196)$. No appreciable differences in the strength of the relationships were observed comparing them with Fig. 6a-d, except for the Mali area, which showed no relationship between data-model agreement and pasture. This is not surprising as the bulk of the $r_{s[\text { NDVI-LAI] values }}$ was $>0.50$. In contrast, the bulk of the $r_{s[\text { NDVI-LAI] }}$ values in the low agreement zone in Chad occupied a much wider range.

Our analysis covers the years 1982-2002, a period for which rainfall appears to have been the main driver of change in the Sahel. It is conceivable that the impact that people have on vegetation dynamics will become greater in the coming decades as the landscape is transformed by human activities. For example Taylor et al. (2002), used a detailed land use model to project accelerating change in the composition of land cover between the mid-1990s and 2015 based on shifting demographics, extensification, livestock population, etc. They also showed that by 2015 , such changes in land cover could lead to a reduction in rainfall by almost $9 \%$ (this estimate does not take into consideration potential magnification of this reduction to feedbacks between the land surface and atmosphere).

Our experimental design carries with it the assumption that random or negative data-model agreement would be attributed to the direct impact that people or animals have had on the landscape, but other factors may also be important in certain areas. For example, low data-model agreement could be caused by poor performance of the vegetation model and error in model input in terms of soil texture and climate data. Soils in the LPJ-DGVM are derived from Food and Agriculture Administration's Soil Map of the World. The soils are divided into two layers of constant depth and textures are assigned according to Zobler (1986). For a complete description of the hydrology, see Sitch et al. (2003). The Soil Map of the World is a highly generalized product where vector polygons are used for mapping soil attributes. Therefore the true heterogeneity of soil attributes is not captured. The absolute values of some of the hydrological output (and therefore associated vegetation predictions) may be inaccurate, but we expect fluctuations in such variables are to be more accurate. As we have applied a parametric measure of data-model agreement in the temporal domain (that would the effect of non-linearity, for example) we would expect to minimize this error. The climate data might be a particular source of error in central and Northern Niger and Northern and Central Chad where low or negative data-model agreement coincides with a relatively low number of precipitation stations (New et al.,
2002). The situation is compounded by scattered mountain ranges where a larger number of climate stations would be necessary to derive reliable gridded data. However, the good agreement between modelled and observed trends at the aggregated level (Fig. 2) and across large areas of the study area (Fig. 3b), and various tests of the LPJ model in general (see model description) suggest that LPJ is capable of reproducing changes in vegetation greenness in the Sahel when driven with the CRU05 climate data. Nevertheless it is impossible to quantify this potential source of error.

Regarding satellite data, NDVI observations from NOAA are affected by various sources of noise, but observations over the Sahel are less affected by cloud contamination than more humid areas (Chappell et al., 2001). Furthermore, the NDVI is fairly sensitive to vegetation changes since NDVI values are below the point of saturation for large parts of the growing season. Systematic shifts due to orbital drift and sensor differences during the observation period are concerns but a recent analysis showed that trends in a related AVHRR data product (NOAA/NASA Pathfinder AVHRR Land Data Set) were not affected by solar zenith angle variations (Lindström et al., 2006). Detecting trends over short time periods using generally noisy satellite sensor data with ordinary least-squares regression is problematic due to the low number of observations, but a spatio-temporal statistical model that more efficiently analyzes the trends has been tested over the Sahel and generates homogeneous areas of strong and statistically significant areas of change (Bolin et al., 2008). Finally, locust swarms are a possible reason for reduced data-model agreement in some areas but the effect is likely marginal. Tratalos and Cheke (2006) emphasize that locusts are usually found for areas receiving above normal rainfall and are associated with good harvests. Moreover, such occurrences are likely to have only short-term impacts in individual years (Hermann et al., 2005).

We have conducted this study using highly generalized data sets with respect to information content and spatiotemporal resolution. Though the AL2000 is the most robust, comprehensive, widely available characterization of agricultural activity at a global extent, it summarizes agricultural status for roughly the year 2000 (near the end of the study period), while our study considers vegetation dynamics for the period 1982 to 2002 (Ramankutty et al., 2008). Factors that may cause land degradation such as shortening of fallow cycles, decreased fertilizer, and limited herd mobility in times of drought, etc. are not captured. We have also aggregated cell size to $0.5^{\circ}$ in order to be able to compare observed and simulated vegetation dynamics which resulted in a loss of spatial fidelity. Additionally, the definition of pasture and cropping in the AL2000 product follows the definition from the Food and Agricultural Organization, but there has been confusion regarding the characterization of both croplands and pasture, especially in census data (Ramankutty et al., 2008). For example, areas designated as cropland may actually be fallow for long periods of time. Much of the 
agricultural land is also multifunctional, though it has not been possible to incorporate this type of information into these data products. Regarding population data, they have not been evaluated thoroughly for Africa, though evaluation of the Asia Population Distribution Database (derived using the same methods) shows good agreement for relatively homogeneous regions, but agreement drops where population distribution is scattered (Nelson, 2004).

LAI and NDVI are widely used variables for characterizing vegetation structure, which are also highly relevant for vegetation functioning (e.g. photosynthesis, NPP, transpiration and interception). But some aspects of vegetation dynamics might not be covered by these variables. Structurally very different vegetation types, such as grassland, shrubland or savanna, can have similar LAI and NDVI, and there can be substantial turnover of species without any effects on vegetation structure. For example, new plant species gaining a foothold through agricultural extensification or land abandonment could respond in a similar way to rainfall than the vegetation they are replacing, and subtle differences in vegetation response may not be able to be picked up using our methodology at this level of spatial aggregation. Along similar lines, an invasion of locally exotic plant species may also result in little or no change in peak growing-season biomass levels (Evans and Geerken, 2004). However, if humans were a major driver of vegetation dynamics in the Sahel, one would also expect some influence on vegetation greenness.

In summary, there exist a number of potential sources of error in our analyses, but the consistency and robustness of our results suggest that the general conclusions of our study hold true.

\section{Conclusions}

We tested the hypothesis that people have had a measurable impact on vegetation dynamics across the Sahel for the period 1982-2002. To the best of our knowledge, this is the first study to tackle this question at the Sahel-wide extent. Our methodology rests on the assumptions that low or negative agreement between simulated and observed vegetation dynamics would be related to the impact that people have on vegetation. But our results indicate that there is generally no relationship between data-model agreement and the best available estimates of population density and agricultural activity. However, a positive relationship was established between level of data-model agreement and pasture intensity, indicating that animal presence did not appreciably affect vegetation dynamics in the region over the period. Either people have not had a significant impact on vegetation dynamics across the Sahel, or the identification of a human "footprint" is precluded by inconsistent or subtle vegetation response to complex socio-environmental interactions, and/or data limitations. Finally, we do not exclude the pos- sibility of a greater human influence on vegetation dynamics over the coming decades with changing land use.

Acknowledgements. This work was partly funded by a Discovery Grant to J. W. Seaquist from the Natural Sciences and Engineering Research Council of Canada. T. Hickler acknowledges funding from the European Commission's 6th Framework Programme ENSEMBLES (contract number GOCE-CT-2003-505539) while L. Eklundh and J. Ardö were supported by the Swedish National Space Board (contracts 87/07 and 120/06 respectively). We thank C. J. Tucker and co-investigators at the NASA/GSFC Global Inventory Modeling and Mapping Studies (GIMMS) group for providing access to the AVHRR NDVI data. The CRU05 climate data were supplied courtesy of the Climatic Research Unit, University of East Anglia. We also thank B. Smith for providing the LPJ code and P. Miller for formatting the climate input data. Finally, we are indebted to E. Lambin and N. Zeng for their valuable insights and comments.

Edited by: V. Brovkin

\section{References}

Behnke, R. H. and Scoones, I.: Rethinking range ecology implications for range management in Africa, edited by: Behnke, R. H., Scoones, I., and Kerven, C., Range Ecology at Disequilibrium, New Models of Natural Variability and Pastoral Adaptation in African Savannas, Overseas Development Institute, London, 130, 1993.

Bolin, D., Lindström, J., Eklundh, L., and Lindgren, F.: Fast estimation of spatially dependent temporal vegetation trends using Gaussian Markov Random Fields, Comput. Stat. Data An., doi:10.1016/j.csda.2008.09.017, in press, 2008.

Chappell, A., Seaquist, J. W., and Eklundh, L.: Improving the estimation of noise from NOAA AVHRR NDVI for Africa using geostatistics, Int. J. Remote Sens., 22, 1067-1080, 2001.

Eklundh, L. and Olsson, L.: Vegetation index trends for the African Sahel, Geophys. Res. Lett., 30, 1430-1433, 2003.

Evans, J. and Geerken, R.: Discrimination between climate and human-induced dryland degradation, J. Arid Environ., 57, 535554, 2004.

Foley, J. A., Coe, M. T., Scheffer, M., and Wang, G.: Regime shifts in the Sahara and Sahel: interactions between ecological and climate systems in northern Africa, Ecosystems, 6, 524-539, 2003.

Gerten, D., Schabhoff, S., Haberlandt, U., Lucht, W., and Sitch, S.: Terrestrial vegetation and water balance - hydrological evaluation of a dynamic global vegetation model, J. Hydrol., 286, 249-270, 2004.

Hein, L. and de Ridder, N.: Desertification in the Sahel: a reinterpretation, Glob. Change Biol., 12, 751-758, 2006.

Helldén, U.: Desertification: time for an assessment?, Ambio, 20, 372-383, 1991.

Hermann, S. M., Anyamba, A., and Tucker, C. J.: Recent trends in vegetation dynamics in the African Sahel and their relationship to climate, Global Environ. Chang., 15, 394-404, 2005.

Heumann, B. W., Seaquist, J. W., Eklundh, L., and Jönsson, P.: AVHRR derived phenological change in the Sahel and Soudan, Africa, 1982-2005, Remote Sens. Environ., 108, 385-392, 2007. 
Hickler, T., Eklundh, L., Seaquist, J. W., Smith, B., Ardö, J., Olsson, L., Sykes, M. T., and Sjöström, M.: Precipitation controls Sahel greening trend, Geophys. Res. Lett., 32, L21415, doi:10.1029/2005GL024370, 2005.

Hickler, T., Prentice, I. C., Smith, B., Sykes, M. T., and Zaehle, S.: Implementing plant hydraulic architecture within the LPJ Dynamic Global Vegetation Model, Global Ecol. Biogeogr., 15, 567-577, 2006.

Holben, B. N.: Characteristics of maximum-value composite images from temporal AVHRR data, Int. J. Remote Sens., 7, 14171437, 1986.

Hulme, M.: Climatic perspectives on Sahelian desiccation, Global Environ. Chang., 11, 19-29, 2001.

Lindström, J., Eklundh, L., Holst, J., and Holst, U.: Influence of solar zenith angles on observed trends in the NOAA/NASA 8 $\mathrm{km}$ Pathfinder normalized difference vegetation index over the African Sahel, Int. J. Remote Sens., 27, 1973-1991, 2006.

Li, J., Lewis, J., Rowland, J., Tappan, G., and Tieszen, L. L.: Evaluation of land peformance in Senegal using multi-temporal NDVI and rainfall series, J. Arid Environ., 59, 463-480, 2004.

Lucht, W., Prentice, I. C., Myneni, R. B., Sitch, S., Friedlingstein, P., Cramer, W., Bousquet, P., Buermann, W., and Smith, B.: Climatic control of the high-latitude vegetation greening trend and Pinatubo effect, Science, 296, 1687-1689, 2002.

McGuire, A. D., Sitch, S., Clein, J. S., Dargaville, R., Esser, G., Foley, J., Heimann, M., Joos, F., Kaplan, J., Kicklighter, D. W., Meier, R. A., Melillo, J. M., Moore, B., Prentice, I. C., Ramankutty, N., Reichenaum, T., Schloss, A., Tian, H., Williams, L. J., and Wittenberg, U.: Carbon balance of the terrestrial biosphere in the twentieth century: analyses of $\mathrm{CO}_{2}$, climate and land use effects with four process-based ecosystem models, Global Biogeochem. Cy., 15, 183-206, 2001.

McGrew Jr., J. C. and Monroe, C. B.: An Introduction to Statistical Problem Solving in Geography, McGraw Hill, New York, 254 pp., 2000.

Mitchell, T. D. and Jones, P. D.: An improved method of constructing a database of monthly climate observations and associated high-resolution grids, Int. J. Climatol., 25, 693-712, 2005.

Nelson, A.: African Population Database Documentation, http://na. unep.net/globalpop/africa/Africa_index.html, 2004.

New, M., Lister, D., Hulme, M., and Makin, I.: A high-resolution data set of surface climate over global land areas, Climate Res., 21, 1-25, 2002.

Olsson, L., Eklundh, L., and Ardö, J.: A recent greening of the Sahel - trends, patterns and potential causes, J. Arid Environ., 63, 556-566, 2005.

Prince, S. D.: A model of regional primary production for use with coarse resolution satellite data, Int. J. Remote Sens., 12, 13131330.

Prince, S. D., Wessels, K. J., Tucker, C. J., and Nicholson, S. E.: Desertification in the Sahel: a reinterpretation of an interpretation, Glob. Change Biol., 13, 1308-1313, 2007.

Ramankutty, N., Evan, A. T., Monfreda, C., and Foley, J. A.: 1. Geographic distribution of global agricultural lands in the year 2000, Global Biogeochem. Cy., 22, GB1003, doi:10.1029/2007GB002952, 2008.
Seaquist, J. W., Olsson, L., Ardö, J., and Eklundh, L.: Broad-scale increase in NPP quantified for the African Sahel 1982-1999, Int. J. Remote Sens., 27, 5115-5122, 2006.

Sellers, P. J.: Vegetation canopy spectral reflectance and biophysical processes, edited by: Asrar, G., Theory and Applications of Optical Remote Sensing, Wiley, New York, 297-335, 1989.

Sitch, S., Smith, B., Prentice, I. C., Arneth, A., Bondeau, A., Cramer, W., Kaplan, J., Levis, S., Lucht, W., Sykes, M., Thonicke, K., and Venevsky, S.: Evaluation of ecosystem dynamics, plant geography and terrestrial carbon cycling in the LPJ Dynamic Global Vegetation Model, Glob. Change Biol., 9, 161185, 2003.

Smith, B., Prentice, I. C., and Sykes, M. T.: Representation of vegetation dynamics in modelling of terrestrial ecosystems: comparing two contrasting approaches within European climate space, Global Ecol. Biogeogr., 10, 621-637, 2001.

Taylor, C. M., Lambin, E. F., Stephenne, N., Harding, R. J., and Essery, R. L. H.: The influence of land use change on climate in the Sahel, J. Climate, 15, 3615-3629. 2002.

Tratalos, J. A. and Cheke, R. A.: Can NDVI GAC imagery be used to monitor desert locust breeding areas?, J. Arid Environ., 64, 342-356, 2006.

Tucker, C. J., Dregne, H. E., and Newcomb, W. W.: Expansion and contraction of the Sahara Desert from 1980 to 1990, Science, 253, 299-301, 1991.

Tucker, C. J., Pinzon, J. E., Brown, M. E., Slayback, D. A., Pak, E. W., Mahoney, R., Vermote, E. F., and El Saleous, N.: An extended AVHRR $8 \mathrm{~km}$ NDVI dataset compatible with MODIS and SPOT vegetation NDVI data, Int. J. Remote Sens., 26, 44854498, 2005.

Turner, M. D.: Methodological reflections on the use of remote sensing and geographic information science in human ecological research, Hum. Ecol., 31, 255-279, 2003.

Wang, G. and Elthahir, E. A. B.: Role of vegetation dynamics in enhancing the low frequency variability of the Sahel rainfall, Water Resour. Res., 36, 1013-1021, 2000.

Wessels, K. J., Prince, S. D., Malherbe, J., Small, J., Frost, P. E., and VanZyl, D.: Can human-induced land degradation be distinguished from the effects of rainfall variability? A case study in South Africa, J. Arid Environ., 68, 271-297, 2007.

Zaehle, S., Smith, B., and Hatterman, F.: Effects of parameter uncertainties on the modelling of terrestrial biosphere dynamics, Global Biogeochem. Cy., 19, GB3020, doi:10.1029/2004GB002395, 2005.

Zeng, N., Neelin, J. D., Lau, K. M., and Tucker, C. J.: Enhancement of interdecadal climate variability in the Sahel by vegetation interaction, Science, 286, 1537-1540, 1999.

Zobler, L.: A World Soil File for Global Climate Modelling, NASA Technical Memorandum 87802, NASA Goddard Institute for Space Studies, New York, New York, USA, 1986. 